\title{
A Pesquisa de Tendências \\ e a Gestão de Marcas de \\ Moda na Sociedade de \\ Hiperconsumo Moderna
}

- Patricia Ceccato'

- Luiz Salomão Ribas Gomez² 


\title{
A Pesquisa De Tendências E A Gestão De Marcas De Moda Na Sociedade De Hiperconsumo Moderna
}

\section{RESUMO}

A sociedade moderna caracteriza-se pela generalização da moda, que é a valorização do novo. Marcas de moda, portanto, são aquelas cujos produtos renovam-se ciclicamente, apresentando modificações constantemente. Em que sentido essas mudanças tendem a ocorrer é o que buscam prever as pesquisas de tendências, realizadas de maneira profissional pelos bureaux de estilo. A sociedade contemporânea é marcada também pelo hiperconsumo, em que os indivíduos adquirem muito mais que a funcionalidade dos produtos: eles buscam "experenciar" sensações, sentimentos, compartilhar valores, estilos de vida e personalidades. Nesse sentido, as marcas atribuem muito mais que uma assinatura aos produtos, mas sua gestão, ou branding, visa associar a seus nomes uma série de atributos intangíveis com os quais se identifique um grupo de consumidores. O objetivo deste estudo, nesse cenário, é descrever e analisar as relações entre a moda, o hiperconsumo, a gestão de marcas e a pesquisa de tendências na sociedade moderna.

Palavras-chave: tendências de moda, branding, sociedade moderna.

\section{Trends Research And Fashion Branding In Modern Hiperconsumption Society}

\begin{abstract}
Modern society is characterized by the generalization of fashion, which is the appreciation of the new. Fashion brands, therefore, are those whose products renew cyclically, constantly changing. In what sense these changes tend to occur is what trends researches, carried out professionally by style 'bureaux', trie to predict. Contemporary society is also marked by hyperconsumption, in which individuals acquire much more than the functionality of products: they seek to experience sensations, feelings, share values, lifestyles and personalities. In this sense, brands atribute much more than a signature to the products, but their management, or branding, aims to associate to their names a series of intangible atributes with which a group of consumers identifies. The purpose of this study, in this scenario, is to describe and analyze the relationships between fashion, hyperconsumption, branding and trends research in modern society.
\end{abstract}

Keywords: fashion trends, branding, modern society. 


\section{INTRODUÇÃO}

"A moda é o que sai de moda" (Coco Chanel).

Apesar de estarem relacionados, moda e vestuário são conceitos distintos. $O$ vestuário permite 0 exercício da moda, ou seja, permite a construção de discursos sobre o corpo vestido. Já a moda se configura como ethos, um valor intrínseco à sociedade, sobretudo a moderna, numa ordem que extrapola os objetos táteis, ao contrário das roupas: "a moda, enquanto dimensão de comunicação da sociedade moderna, é campo privilegiado da experiência estética, pois se constitui como ethos firmado no prazer de ver e ser visto" (LIPOVETSKY, 1989, p.28). Ela consagra explicitamente a iniciativa estética, a fantasia, a originalidade humana, e implica, além disso, uma ordem de valor que exalta o presente novo em oposição [...] ao passado coletivo. Não há sistema de moda senão quando o gosto pelas novidades se torna um princípio constante e regular, $[. .$.$] quando funciona$ como exigência cultural autônoma (IDEM, p.29).

A moda, sabendo-se disso, foi tratada aqui como expressão comportamental dos indivíduos, como um domínio através do qual podem traduzir seus anseios de novidade e diferenciação, não como produto ou mercado de tendências. $O$ vestuário se constitui como a manifestação mais pura da moda, pois renovase constantemente, traduzindo sobre o corpo o discurso que diz "eu visto o que é novo". Porém, nesse trabalho, moda representa muito mais que o vestuário: qualquer produto cujo design é renovado com regularidade.

Entretanto, a moda é campo privilegiado da experiência estética, e permite, sobretudo na apropriação dos objetos da vestimenta, o usufruto de uma infinidade de signos que operam a subjetividade de cada sujeito, diariamente (SANT'ANNA, 2003). "Os modos de se vestir, de se adornar, de interferir sobre 
os corpos, são elementos que se compõem com outros vetores, os quais produzem os modos de ser, os modos de relação a si: as subjetividades" (MESQUITA, 2004, p.15). Muito mais que traduzir a alma da moda, o vestuário traduz personalidades.

"A moda se compõe no 'espírito do tempo' de cada sociedade. Cada época tece determinadas formas, e é principalmente sobre a pele, 'uma subjetividade' que ganhou o lugar privilegiado de estar ao mesmo tempo no corpo e no mundo" (SANT'ANNA, 1995) que elas se apresentam de maneira mais clara e direta. Portanto, a aparência, e o vestuário em si, são aspectos fundamentais na mediação entre os indivíduos na sociedade moderna. Sendo assim, "as roupas, por serem signos que carregam em si uma série de significados atrelados à beleza, à juventude, à riqueza, à feminilidade ou à masculinidade, à alegria ou tristeza imprimem ao seu portador uma escolha diária de posicionamento no conjunto maior das teias de significados compostos da cultura" (SANT'ANNA, 2003).

Sabendo disso, e devido a grande importância da moda como comportamento, e das roupas como constituinte da aparência, bem como a influência das mesmas nas relações sociais contemporâneas, as marcas de vestuário são incumbidas da difícil tarefa de traduzir em produtos os anseios e a personalidade do seu público-alvo, além de incorporar o novo, de apresentar elementos de design alinhados com as tendências efêmeras da moda.

E claro, numa sociedade em que as marcas vêm ganhando cada vez mais importância na relação entre indivíduo e produto, as marcas, principalmente do setor de vestuário e outros produtos renovados ciclicamente, como objetos de decoração, automóveis, eletrodomésticos e eletrônicos, entre outros; vêm investindo muito no desenvolvimento de inovações e pesquisas de tendências de consumo e comportamento, que possibilitem agregar valores intangíveis aos seus produtos alinhados com os anseios da sociedade, como forma de vencer a competitividade.

Com esse intuito, servem-se dos resultados de pesquisas de tendências, realizadas de maneira 
profissional pelos bureaux de estilo, que buscam prever em que sentido as mudanças de comportamento e design tendem a ocorrer. Portanto, nesse trabalho, tendência de moda representa mais do que as tendências que influenciam as transformações efêmeras do vestuário - ainda que os bureaux foquem nesse setor os seus resultados -, e sim o sentido em que as mudanças no consumo, nas relações sociais, nos gostos pessoais, nas tecnologias, materiais, projetos e estética tendem a acontecer e influenciar mudanças em diversas áreas e produtos diferentes.

Como a sociedade contemporânea é marcada também pelo hiperconsumo, em que os indivíduos adquirem muito mais que a funcionalidade dos produtos, buscando "experenciar" sensações, sentimentos, compartilhar valores, estilos de vida e personalidades, as marcas atribuem muito mais que uma assinatura aos produtos, mas sua gestão, ou branding, visa associar a seus nomes essa série de atributos intangíveis com os quais se identifique um grupo de consumidores. Nesse contexto, é fundamental entender as relações entre a moda, o hiperconsumo, a gestão de marcas e a pesquisa de tendências na sociedade moderna. Esse trabalho busca, portanto, descrever e analisar como esses conceitos estão relacionados na sociedade moderna.

\section{METODOLOGIA}

O objetivo deste trabalho é realizar uma análise do consumo na sociedade moderna no que tange à dinâmica das tendências de moda e sua implicação na gestão de marcas. Sobretudo nas marcas de vestuário, que se caracterizam pela comercialização não só de produtos, mas de valores como mudança e novidade. Para desempenhar tal análise, a pesquisa se vale de uma investigação bibliográfica que abrange publicações das áreas de filosofia - que tratam da sociedade de consumo -, moda, tendências e gestão de marcas. A proposta é fazer uma pesquisa de cunho qualitativo, 
visando analisar as características culturais da sociedade moderna com implicações no consumo.

Enquanto estudos quantitativos geralmente
procuram seguir com rigor um plano
previamente estabelecido (baseado em
hipóteses claramente indicadas e variáveis que
são objeto de definição operacional), a
pesquisa qualitativa costuma ser direcionada
ao longo do seu desenvolvimento, além disso,
não busca enumerar ou medir eventos e,
geralmente, não emprega instrumental
estatístico para análise dos dados; seu foco de
interesse é amplo e parte de uma perspectiva
diferenciada da adotada pelos métodos
quantitativos. Dela faz parte a obtenção de
dados descritivos mediante contato direto e
interativo do pesquisador com a situação
objeto de estudo (NEVES, 1996, p.01).

De acordo com Lopes (1990), "comumente o uso de métodos estatísticos gera pesquisas descritivas, enquanto métodos qualitativos produzem pesquisas interpretativas". Nesse caso, desenvolve-se, portanto, uma pesquisa descritiva, e posteriormente, interpretativa dos dados. "A descrição faz a ponte entre a fase de observação dos dados e a fase da interpretação" (IDEM, p.129).

Assim, segue-se à descrição dos dados coletados, a interpretação dos mesmos à luz da bibliografia pesquisada. De acordo com Lopes (1990), "a interpretação é a segunda etapa da análise e com ela a pesquisa atinge a condição própria de cientificidade". Neste trabalho, por conseguinte, os dados bibliográficos coletados sobre a sociedade de consumo moderna são descritos e posteriormente interpretados sob o viés da gestão de marcas e teoria das tendências, visando analisar a relação entre os fenômenos da moda e do hiperconsumo e suas implicações nas tendências e marcas.

Uma marca, nesse contexto, é aqui considerada "um nome, termo, sinal, símbolo ou combinação dos mesmos, que têm o propósito de identificar bens ou serviços de um vendedor ou grupo de vendedores e de diferenciá-los de concorrentes" (KOTLER, 1998, p.393). Segundo Strunk (2003, p.18), a marca pode ser 
considerada a soma intangível dos atributos de um produto: seu nome, embalagem e preço, sua história, reputação, e a maneira como ele é promovido. "É alguma coisa que nos marca, sobre a qual temos uma opinião e nos deixamos ou não seduzir pelos seus encantos, ao ponto de aceitarmos consumar uma relação que, normalmente, envolve dinheiro" (COELHO, 2007).

De acordo com Gobé (2002, p.20) é crucial que para serem relevantes "as marcas compreendam as grandes mudanças agindo e concorrendo diferentemente. Hoje estamos claramente operando com um conjunto de valores completamente diferente do que conhecíamos há cinco anos. A velocidade substitui a estabilidade; os valores intangíveis se tornam mais valiosos que os tangíveis". Sabendo disso, os profissionais incumbidos da gestão das marcas de vestuário têm se beneficiado, cada vez mais, de branding e das pesquisas de tendências como áreas informacionais para criação e manutenção de marcas de sucesso na sociedade moderna.

\section{O HIPERCONSUMO NA IDADE MODERNA}

Não é de hoje que ouvimos falar na sociedade de consumo, que surge a partir da revolução industrial, por volta dos anos 80 do século XIX. Segundo Lipovetsky (2007, p.24), primeiramente, ela se caracteriza pelo consumo de massa, possibilitado pela expansão dos mercados através da melhora das infraestruturas modernas de transporte e comunicação, além do aperfeiçoamento de máquinas de fabrico. Estes melhoramentos permitiram o aumento da produtividade com custos mais reduzidos e o escoamento regular de enormes quantidades de produtos.

Mas não só isso, "o capitalismo de consumo [...] foi também uma construção cultural e social que exigiu a 'educação' dos consumidores e necessitou do espírito visionário de empresários criativos, a 'mão dos gestores'" (LIPOVETSKY, 2007, p.24-25). Um número maior de produtos tornou-se acessível a um número 
maior de consumidores. É a época do marketing de massa, dos grandes armazéns, das marcas nacionais, das embalagens e da publicidade nacional: "estandardizados, acondicionados em pequenas embalagens distribuídos pelos mercados nacionais, os produtos passam a apresentar um nome, atribuído pelo fabricante: a marca." (IDEM, p.26)

A partir da segunda metade do século $X X$ vemos nascer uma nova modernidade. Segundo Lipovetsky (2007, p.07), é nessa época que "a febre do conforto ocupou o lugar das paixões nacionalistas e os lazeres substituíram a revolução". "Se a fase I começou por democratizar a compra dos bens duradouros, a fase II concluiu este processo colocando à disposição de todos, ou quase todos, os produtos emblemáticos da sociedade de afluência: automóvel, televisão, aparelhos eletrodomésticos." (IDEM, p.28).

\begin{abstract}
Realizando o 'milagre de consumo', a fase II dá origem a um poder de compra discricionário em camadas sociais cada vez mais alargadas, que podem aspirar, confiantes, ao melhoramento constante dos seus recursos; difundiu o crédito e permitiu à maioria das pessoas libertarem-se da urgência das necessidades imediatas. Pela primeira vez, as massas ascendem a uma procura material mais psicologizada e mais individualizada, a um modo de vida (bens duradouros, atividades de lazer, férias, moda) até então exclusivo das elites sociais (LIPOVETSKY, 2007, p.29).
\end{abstract}

Esta é a época da diferenciação dos mercados, da moda, da sedução, do efêmero, do marketing segmentado, centrado na idade e nos fatores sócioculturais. "Toda a sociedade se mobiliza em torno do projeto de criar um cotidiano confortável e fácil, sinônimo de felicidade" (LIPOVETSKY, 2007, p.30): "há também todo um ambiente de estimulação dos desejos, a euforia publicitária, a imagem luxuriante de férias, a sexualização dos símbolos e dos corpos" (idem, p.3031). Triunfa a exaltação dos prazeres momentâneos. Lipovetsky defende ainda, uma segunda revolução na sociedade de consumo nas ultimas décadas do século $\mathrm{XX}$ : 
Apoiando-se na nova religião da melhoria continua das condições de vida, o melhor-viver tornou-se uma paixão das massas, o objetivo supremo das sociedades democráticas, um ideal exaltado em cada esquina. [...] Aparentemente nada ou quase nada mudou: continuamos a evoluir na sociedade do supermercado e da publicidade, do automóvel e da televisão. No entanto, nas duas ultimas décadas, [...] uma nova fase do capitalismo de consumo teve início: trata-se precisamente da sociedade de hiperconsumo (LIPOVETSKY, 2007, p.07-08).

Os consumidores tornam-se mais exigentes relativamente à qualidade de vida, de comunicação, de saúde, ao meio-ambiente e às questões sociais: "queremos objetos 'para viver', mais do que objetos para exibir; compramos isto ou aquilo não tanto para ostentar, para evidenciar uma posição social, como para ir ao encontro de satisfações emocionais e corporais, sensoriais e estéticas, relacionais e sanitárias, lúdicas e recreativas" (LIPOVETSKY, 2007, p.36). "O apogeu do consumo já não tem a ver com o signo diferencial, mas com o valor experimental, o consumo 'puro' que funciona não como significante social, mas como panóplia de serviços destinados ao indivíduo" (idem, p.37).

O consumidor deixa de consumir apenas produtos, e passa a buscar muito mais que isso: "o hiperconsumidor já não procura tanto a posse das coisas por elas mesmas, mas, sobretudo, a multiplicação das experiências, o prazer da experiência pela experiência, a embriaguês das sensações e das emoções novas" (LIPOVETSKY, 2007, p.54). Esses fenômenos, ao não abdicarem em nada do espírito, privilegiam a experiência, a interatividade, os sentidos humanos (MAFFESOLI, 2004, p.149).

Para Solomon (2011, p.43-44), "muitas vezes, as pessoas compram produtos não pelo que eles fazem, mas pelo que eles significam". Isso não implica que a função básica de um produto não tenha importância, mas sim que o papel que ele exerce em nossas vidas vai bem além. "O objeto perde a finalidade objetiva e a respectiva função, tornando-se termo de todas as significações" (BAUDRILLARD, 2008, p.146). 
"Quando os produtos são similares, por exemplo, costumamos escolher a marca que tenha uma imagem (ou até mesmo uma personalidade) que combine com a nossa". Atualmente, defende Solomon (2011, p.44), nós, consumidores (hiper)modernos, por um lado, desejamos cada vez mais espetáculos desmesurados, por outro, ansiamos por um mundo intimo ou 'verdadeiro' que se identifique conosco (LIPOVETSKY, 2007). Tal é a forma característica do objeto-mercadoria contemporâneo: ser feito à nossa imagem e semelhança, como um decalque que é também um retrato (VOLLI, 2006). A verdade é que cada vez mais o consumo é justificado pela proporção de felicidade ao indivíduo: buscam-se experiências positivas, motivadoras, relaxantes, afetivas. "O hiperconsumidor não se limita a adquirir produtos de alta tecnologia para comunicar em tempo real: compra também produtos afetivos" (LIPOVETSKY, 2007, p.63).

Atualmente, durante o que Maffesoli (2004, p.125) chama de "reencantamento do mundo", os objetos são imbuídos de signos que não são eles próprios, mas que remetem a outros significados. Segundo Jean Baudrillard (2008, p.26), "vivemos desta maneira ao abrigo dos signos e na recusa do real. Segurança miraculosa: ao contemplarmos as imagens do mundo, quem distinguirá esta breve irrupção da realidade do prazer profundo de nela não participar?". Para o autor (idem), "a imagem, o signo, a mensagem, tudo que 'consumimos', é a própria tranquilidade selada pela distância ao mundo e que ilude, mais do que compromete, a alusão violenta ao real". O consumo "tende para a felicidade por defeito, eliminando as tensões" (BAUDRILLARD, 2008, p.27) e segundo Ugo Volli (2006, p.214), "o comportamento do consumidor perante as mercadorias já não é mais das vezes de fato técnico, neutral, objetivo; não atende apenas às prestações e ao custo das mercadorias, à relação entre preço e qualidade". Fica claro que, atualmente, "o nível afetivo é central em toda relação de consumo" (idem):

A civilização do bem-estar consumista constituiu o grande coveiro histórico da ideologia gloriosa do dever. Ao longo da 
segunda metade do século, a lógica do consumo de massas dissolveu o universo das homilias moralizadoras, erradicou os imperativos rigoristas e engendrou uma cultura onde a felicidade se impõe como mandamento moral, os prazeres ao proibido, a sedução à obrigação. [...] O culto da felicidade em massa veio generalizar a legitimidade dos prazeres e contribuir para a promoção da febre da autonomia individual (LIPOVETSKY, 2004, p.60).

Segundo Lipovetsky (2007, p.36), "já não esperamos tanto que as coisas nos classifiquem face aos outros, mas que nos permitam ser mais independentes e ter mais mobilidade, usufruir de sensações, viver experiências, melhorar a nossa qualidade de vida, conservar a juventude e a saúde". É a era do consumo individualista: "o consumo do individuo 'para si' suplantou o consumo 'para o outro'".

As pessoas buscam exaltar sua individualidade ao consumir, e os produtos vêm atender às suas expectativas: "atualmente, nada se consome de modo puro e simples, isto é, nada se compra, possui e utiliza para determinado fim" (BAUDRILLARD, 2008, p.213), os objetos deixam de atender apenas às suas funções, mas "acima de tudo, se destinam a servir vossa excelência [...]. Sem a ideologia total da prestação pessoal, o consumo não seria o que é" (idem). É a tal "cultura materialista e hedonista, baseada na exaltação do eu", de que trata Lipovetsky (2004, p.60): "uma nova civilização foi edificada, a qual já não se propõe estrangular 0 desejo, mas que o exacerba e o desculpabiliza: o usufruto do presente, o templo do eu, do corpo e do conforto tornaram-se a nova Jerusalém dos tempos pós-moralistas".

Segundo o autor (2007, p.98), "a fragmentação dos sentimentos e das imposições de classe criou a possibilidade de escolhas particulares e abriu caminho à livre expressão dos prazeres e dos gostos pessoais". A princípio, pode parecer que essa capacidade é do produto, mas somos nós que os impregnamos de significados: "os objetos seduzem-nos porque têm necessidade de nós para existirem. Sem consumidores 
'pós-modernos' não há mercadorias sedutoras" (VOLLI, 2006, p.217).

\begin{abstract}
A este respeito, Nietzche tinha razão: a ilusão, a ficção, as representações são necessárias à vida porque é preciso que a vida inspire confiança. Assim, é errado encarar as promessas da sociedade de hiperconsumo como um sistema de intimidação e de culpabilização quando estas são, em primeiro lugar, um complexo de mitos, sonhos, significações imaginárias que, criando objetivos e promovendo a confiança no futuro, favorecem a reoxigenação de um presente muitas vezes desgastado (LIPOVETSKY, 2007, p.290).
\end{abstract}

Isso quer dizer que o objeto acaba sendo um "sujeito 'passivo' que ele [o indivíduo] utilizará para sustentar a sua própria identidade. [...] O homem se reconhece nas mercadorias" (VOLLI, 2006, p.215), e o objetivo delas não é apenas "dirigir mecânica ou psicologicamente um consumidor reduzido ao papel de objeto, mas estabelecer uma relação de conivência, brincar com o público, fazê-lo partilhar um sistema de valores, criar uma proximidade emocional ou um elo de cumplicidade" (LIPOVETSKY, 2007, p.156).

Os produtos vieram não seduzir o homem e obrigá-lo a consumir, mas vieram se oferecer para consumo a um homem que quer ser seduzido. 0 homem busca a felicidade, e os objetos não "tratam apenas de estimular as necessidades e os reflexos condicionados, mas também de criar ligações emocionais com a marca, passando a promoção da imagem a ser mais importante que a do produto" (LIPOVETSKY, 2007, p.151). Ou seja, culturalmente temos buscado uma proximidade emocional com o mundo que nos permita exercemos a nossa própria individualidade, e as marcas vieram atender a esta demanda.

"A primeira vista, o valor parece residir nas coisas, mas assim que fixamos um pouco melhor o olhar, aparece-nos também como um derivado do nosso próprio desejo, socialmente realizado" (VOLLI, 2006, p.185). Boorstin exprime a ideia de que é preciso 
desculpar os publicitários: a persuasão e a mistificação não provêm tanto da sua falta de escrúpulos, quanto do prazer que temos em ser enganados: procedem menos do seu desejo de seduzir do que do nosso desejo de ser seduzidos (BAUDRILLARD, 2008, p.166).

\section{A MODA NA SOCIEDADE DE HIPERCONSUMO}

Segundo Lipovetsky (2007), entramos no universo do hiperconsumo quando o gosto pela mudança se difundiu universalmente, quando o desejo de 'moda' ultrapassou a esfera da indumentária, quando a paixão pela renovação adquiriu uma espécie de autonomia que torna secundárias as lutas de status.

Conforme o autor (2007, p.37), "o gosto pelas novidades mudou de sentido": o culto do novo nada tem de recente, visto que se impôs logo em finais da Idade Média, nomeadamente através da emergência da moda. Mas "contudo, durante séculos, a norma de adotar a novidade não ultrapassou os círculos restritos dos privilegiados, assentando em larga medida no seu valor distintivo" (idem).

Lipovetsky (1989, p.29), esclarece que sempre houve diferenças no vestuário como forma de distinção social, mas que "não há sistema de moda senão quando o gosto pelas novidades se torna um princípio constante e regular". De acordo com Lang (2001, p.159), "se a roupa distingue o homem do animal, a moda o define como cidadão". O que significa que moda não é apenas roupa: "o vestuário proporciona o exercício da moda e essa atua no campo do imaginário, dos significantes, é parte integrante da cultura" (SANT'ANNA, 2007, p.74).

"O sistema de moda seria a própria dinâmica que produziu a modernidade" (SANT'ANNA, 2007, p.85), caracterizada por: 1. A desqualificação do passado, e prestígio ao novo e ao moderno; 2 . Crença no poder dos homens para criar seu próprio mundo, buscando dominar a racionalidade como uma afirmação da soberania humana; 3. Adotar a mudança como 
regra permanente da vida; 4. Definição do presente como eixo temporal da vida; 5. Aceitação da variabilidade estética, refinamento do gosto e da sensibilidade estética; 6 . Consagração de iniciativas estéticas, da fantasia e da originalidade como diferencial positivo entre os sujeitos (LIPOVETSKY, 1989 apud SANT'ANNA, 2007).

Sendo assim, podemos conceituar moda como: "ethos das sociedades modernas e individualistas, que, constituído em significante, articula as relações entre os sujeitos sociais a partir da aparência e instaura o novo como categoria de hierarquização dos significados" (SANT'ANNA, 2007, p.88):

\begin{abstract}
Pode-se caracterizar empiricamente a 'sociedade de consumo' por diferentes traços: elevação no nível de vida, abundância das mercadorias e dos serviços, culto dos objetos e dos lazeres, moral hedonista e materialista, etc. Mas, estruturalmente, é a generalização do processo de moda que a define propriamente. A sociedade centrada na expansão das necessidades é, antes de tudo, aquela que reordena a produção e o consumo de massa sob a lei da obsolescência, da sedução e da diversificação (LIPOVETSKY, 1989, p.159).
\end{abstract}

"Eis o ponto fundamental para a definição de consumo", segundo Baudrillard (2008, p.113): "1. Não mais como pratica funcional dos objetos, possessão, etc; 2. Não mais como simples função de prestigio individual ou de grupo; 3. Mas como sistema de comunicação e de permuta, como código de signos continuamente emitidos, recebidos e inventados, como linguagem". Desta forma, pensando no consumo na sociedade hipermoderna, "a marca é o vértice central da constituição e preservação do imaginário que é associado a um produto" (SANT'ANNA, 2007, p.91). "Assim surgem as novas funções subjetivas do consumo" (Lipovetsky, 2007, p.38), e a função das marcas, nesta sociedade de hiperconsumo, é "atribuir aos objetos um valor simbólico que, adequado com as referencias culturais da sociedade, vai permitir ao consumidor a afirmação da sua personalidade $[\ldots]$ 
como fator de identidade, código cultural, mensagem social" (SANT'ANNA, 2007, p.91).

\section{BRANDING E AS MARCAS DE MODA}

Uma marca de moda, atuante na sociedade de hiperconsumo, é aquela em constante evolução, que acompanha as mudanças do seu tempo propostas pela lógica da moda. A marca de moda renova-se para acompanhar as tendências de consumo. E para fazê-lo, imerge-se em valores que são congruentes com a sociedade moderna e seu público consumidor, transmitindo princípios de novidade, mudança, beleza e prazer para aqueles que estão ávidos por consumi-los.

A moda, por permitir a exacerbação das identidades individuais, impregnou os objetos de consumo de valores e personalidades. Este processo se deu quando o ethos moda, em busca de uma "psicologização das marcas", passou a explorar "o impacto, as mini-transgressões, a teatralidade espetacular que seduz" (SANT'ANNA, 2007, p.90-91). As marcas acabam por tornarem-se os instrumentos por meio dos quais os produtos passam a impregnar a lógica da moda.

É fortalecida a lógica do "consumo emocional" (LIPOVETSKY, 2007, p.39), através das marcas, "que gabam os méritos das iniciativas que proporcionam aos consumidores: experiências afetivas, imaginárias e sensoriais", em que, segundo o autor (idem), "já não é a funcionalidade fria que está na ordem do dia, mas a atratividade sensível e emocional".

A gestão de marcas - também chamada de branding - é a 'filosofia corporativa', por assim dizer, que dota as ofertas de valores e personalidades, que permitirão a criação de elos emocionais entre produto e consumidor. Segundo Kotler (apud Tybout \& Calkins, 2006), "branding é muito mais do que dar nome a uma oferta. Ele significa fazer uma promessa aos clientes sobre como viver uma experiência a um nível de desempenhos completos, ou seja, significa 'viver a marca"'. Conforme afirma Gobé (2010), "as marcas 
precisam conectar-se com a cultura e alcançar o coração das pessoas".

Portanto, branding, ou gestão de marcas, é mais do que apenas se certificar de que os clientes reconheçam o logotipo ou o nome de um produto; significa criar uma associação emocional entre o cliente e o produto, serviço ou empresa. Segundo Gobé (2010, p.15), "as marcas devem mudar de 'comunicações' e 'commodities' para emoção e inspiração". Sendo assim, branding é:

O conjunto de ações ligadas à administração das marcas. São ações que, tomadas com conhecimento e competência, levam as marcas além da sua natureza econômica, passando a fazer parte da cultura, e influenciar a vida das pessoas. Ações com a capacidade de simplificar e enriquecer nossas vidas num mundo cada vez mais confuso e complexo (MARTINS, 2006, p.08).

Segundo Martins (2006, p.279), branding descreve "todas as ações relacionadas aos projetos de criação ou gestão de marcas". Não se trata de uma metodologia específica, mas sim de uma filosofia de trabalho que utiliza conceitos de uma série de disciplinas, entre elas as principais são o marketing, a publicidade e o design (GOMEZ et al, 2010), para dotar os produtos de valores e sensações inspirados na cultura.

Nesse contexto, em consonância com a cultura da sociedade moderna, a gestão de marcas tornou o sensível e o emocional objetos de investigação, destinados a "diferenciar as marcas no seio de um universo hipercompetitivo e, por outro [lado], a prometer uma 'aventura sensitiva e emocional' ao hiperconsumidor que busca sensações variadas e melhor-estar ao nível dos sentidos" (LIPOVETSKY, 2007 , p.39). Atualmente, vivemos na era do 'consumo emocional', que designa, à margem dos efeitos de uma tendência de marketing, a forma geral que assume o consumo quando o ato de compra, já não comandado pela preocupação conformista em relação ao outro, adquire uma lógica desinstitucionalizada e interiorizada, 
baseada na procura de sensações e de um melhor-estar subjetivo (idem).

Atualmente, a gestão de marcas, em concordância com as aspirações dos indivíduos, "conseguiu a proeza pós-moralista de conjugar coração e marketing, seriedade e jingle, integridade e espetáculo, ideal e sedução" (LIPOVETSKY, 2004, p.303). Na sociedade de hiperconsumo, "já não é tanto a imagem social e o tornar-se notado que interessa, mas o imaginário da marca" (idem, p.40).

Em assentimento com a lógica da moda, "o que se vende já não é um produto, mas uma visão, um 'conceito', um estilo de vida associado à marca" (LIPOVETSKY, 2007, p.40), que vai permitir aos indivíduos expressarem suas próprias individualidades e visões de mundo, que têm no novo e na mudança um prazer mundano: "nome, logotipo, design, slogan, patrocínio, loja, tudo deve ser mobilizado, redefinido, dotado de um novo visual, com vista a renovar o perfil de imagem, a dar uma alma ou um estilo à marca" (idem). "Todos esses conteúdos se reduzem a signos sobrepostos, culminando no super-signo que é a marca: ou seja, a verdadeira e única mensagem" (BAUDRILLARD, 2008, p.197).

A marca na "época pós-moralista coincide com a da moda generalizada, que conseguiu fagocitar a própria dimensão moral, transformar os valores em objetos" (LIPOVETSKY, 2004, p.286). Nos nossos dias, o entusiasmo pelas marcas alimenta-se do desejo narcisista de gozar o sentimento íntimo de ser uma 'pessoa de qualidade', de nos compararmos aos outros achando-nos em vantagem, de sermos melhores que as massas, sem nos importarmos com a aprovação dos outros ou com o desejo de lhes provocar inveja. O culto contemporâneo das marcas traduz uma nova relação com o luxo e a qualidade de vida (LIPOVETSKY, 2007).

A gestão de marcas, então, transforma os produtos em objetos identitários, no momento em que os engloba com a lógica da moda. Isso irá permitir que os consumidores os utilizem como signos das suas personalidades, como objetos de fetiche que representam mais do que a si próprios, mas 
significados atrelados ao novo, ao desejo de mudança particular dos próprios indivíduos, que, como afirma Lipovetsky (2007, p.41), agora se dão "ao luxo, ao supérfluo, a marcas de qualidade."

"É neste sentido que o consumo é lúdico e que o lúdico do consumo tomou progressivamente o lugar do trágico da identidade" (BAUDRILLARD, 2008, p.263). "O que é que seduz, no ato da compra de produtos não correntes, senão, pelo menos em parte, a emoção nova, por pequena que seja, que acompanha a aquisição de uma coisa?" (LIPOVETSKY, 2007, p.57).

Em primeiro lugar, o apreço pela mudança incessante no consumo já não apresenta limites sociais, tento alcançado todas as camadas e todas as faixas etárias; em segundo lugar, desejamos os novos produtos por si próprios, pelos benefícios subjetivos, funcionais e emocionais que nos proporcionam. [...] A curiosidade tornou-se uma paixão de massas e o mudar por mudar é agora uma experiência com que o indivíduo pretende testar-se a si próprio. O amor pelo novo já não é tão determinado pelas paixões conformistas como pelos apetites experimentadores dos sujeitos (LIPOVETSKY, 2007, p.38).

Através dos processos de branding, a marca de moda se reveste com o caráter do novo, de mudança, dando aos seus consumidores a propriedade de dizer que são indivíduos 'na moda' no momento em que eles consomem, mais do que objetos, mas valores, sentimentos e ideais da cultura moderna. Porém, como manter-se atual? Como reconhecer quais as novidades, as inovações, os anseios dos consumidores na contemporaneidade mais imediata? Como prever quais serão as características, valores e sensações que exprimirão a qualidade distintiva de ser novo, de 'estar na moda', no futuro próximo? 


\section{AS TENDÊNCIAS DE MODA E OS BUREAUX DE ESTILO}

Uma vez que o conceito de moda é a vontade de diferenciação pelo gosto do novo, sendo descrito também como o uso passageiro que regula a forma de vestir (Aguiar, 2006), e que a sociedade moderna é justamente caracterizada pela influência da moda, do desejo pelo novo, em todas as esferas de consumo indo muito além do vestuário -, o que regula o surgimento e adoção de uma novidade?

É certo que os objetos são portadores de significados sociais indexados, de uma hierarquia social e cultural - e este é o menor de seus detalhes: forma, material, cores, durabilidade, arranjo no espaço - em suma, é certo que eles constituem um código (BAUDRILLARD, 1981). Os objetos de consumo, portanto, são signos, pertencentes ao código cultural da sociedade moderna. Um signo tem uma materialidade que percebemos com um ou vários de nossos sentidos. Essa coisa que se percebe está no lugar de outra - está presente para designar ou significar outra coisa, ausente, concreta ou abstrata." (PEIRCE, 1978 apud JOLY, 2007).

As roupas [e qualquer objeto], por serem signos que carregam em si uma série de significados, imprimem ao seu portador uma escolha diária de posicionamento no conjunto maior das teias de significados compostos da cultura (SANT'ANNA, 2003). Esses significados incluem os de conceitos como mudança e inovação que são a incorporação da própria moda aos objetos. Porém, para que eles sejam signos da moda, precisam significar o novo. O consumo, no contexto da sociedade moderna, precisa ocorrer em um ciclo, portanto, de mudança e inovação para que os produtos incorporem o significado do novo.

Duas ideias orientam esse ciclo: antecipação e mudança. Mais do que conhecer o consumidor, é preciso deixar esse conhecimento para trás. A fluidez desse consumidor é a fluidez do conhecimento - ou da ignorância - sobre ele. Serve para explicar o motivo de existir uma necessidade tão incessante de mudança e 
antecipação. Esse consumidor só não se torna peça irrelevante do sistema porque é ele quem compra (BERGAMO, 2007).

O estilo representa um poder mágico de vendagem e distinção de um determinado produto, incorporando, numa linguagem de tendência, a ideia de um suposto saber antecipado sobre o consumidor que tem como pressuposto, necessariamente, a sua constante renovação (BERGAMO, 2007).

Tendências são convergências do gosto coletivo. São pontos focais do desejo por meio dos quais indivíduos muito diferentes se descobrem nas mesmas vontades. Hoje, os desejos da maioria parecem regidos por uma autoridade tão poderosa quanto caprichosa: a moda. Um dia, porém, a moda passa. Compreender as tendências significa penetrar os caminhos de imitação, de difusão dos gostos, e o papel de indicador social que eles podem desempenhar (ERNER, 2015).

O ciclo da moda é definido pela ortodoxia sociológica: um comportamento adotado de maneira temporária por uma parte substancial de um grupo social quando esse comportamento é percebido como socialmente adequado para a época e situação (ERNER, 2015). E é inegável que nas últimas décadas vêm ocorrendo a multiplicação das tendências comerciais. Alguns princípios que regem a moda do vestuário hoje se aplicam a outros âmbitos.

Esse ciclo da moda definido por um saber antecipado, que impele incessantemente para a mudança, acaba por outorgar ao produto um caráter mágico: seu poder de vendagem e de distinção para a empresa perde-se, transfere-se, vai estar em outro produto ao qual se deve chegar antes que 0 concorrente. É necessário, portanto, supor um mecanismo capaz de identificar as transferências operadas por esse poder mágico. É essa a responsabilidade dos bureaux de estilo: prever tais transferências - as tendências de moda que estão por $\operatorname{vir}(B E R G A M O, 2007)$. Prever o que tende a ser o novo "novo" - saber antecipadamente para qual produto o gosto coletivo tende a convergir. 
Os primeiros "bureaux de style" surgiram no final da década de 1950, no mercado francês, com o objetivo de organizar a indústria têxtil através de suas sugestões sobre cores, materiais e formas (LEÃO, 2002). Alguns exemplos são o Bureaux Promostyl, Peclers Paris, e Nelly Rodi. Desde a sua criação, o conselho em tendência se tornou uma atividade econômica consolidada. A maioria dos escritórios conservou um vestígio do seu ofício de origem: aconselhar a linha de produção em moda, ou seja, fiadores e fabricantes de tecidos. É por isso que os bureaux, primeiro, se dedicam às cores, depois aos materiais, e, por fim, às formas. Seu trabalho se organiza em torno de equipes criativas compostas por diretores artísticos e estilistas, às vezes confrontados com pessoas externas à moda - semiólogos, sociólogos ou historiadores da moda (ERNER, 2015).

Porém, no auge de sua "pregação" - nos áureos anos 60 - os bureaux monopolizaram o direito de prever tendências e de comercializa-las, fato este que instituiu uma ordem pragmática e ditatorial sobre as leis estéticas que concebiam (LEÃO, 2002). Os escritórios, ou agências, de estilo fundamentam e elaboram todas as informações necessárias para a criação de tendências de moda, as quais são organizadas em cadernos específicos chamados "cahiers de tendances", que fornecem a segurança necessária ao desenvolvimento de um produto de moda (idem).

A principal atividade das agências é a venda desses "cadernos de tendência", que são apresentados sob a forma de luxuosos guias criativos que misturam gamas de cores, esboços, amostras de tecidos, textos e conceitos. Descobrem-se temas, sugestões de paletas, propostas de estilo (ERNER, 2015). Porém, é importante ressaltar que 0 público-alvo desses cadernos produzidos pelos escritórios de estilo é a indústria, seja a têxtil ou de outros bens de consumo. Trata-se de uma informação especializada de interesse dos fabricantes de matérias-primas e produtos. Os consumidores finais dos objetos ou peças acabadas, desde o início do século XX até hoje, se informam sobre 
as tendências de moda através das revistas, sobretudo as femininas, que informam as tendências que estão já em voga, sem antecipação. Portanto, trata-se mais de um diagnóstico que de uma previsão.

Além das revistas femininas, atualmente outra fonte muito importante de informações sobre tendências são websites e redes sociais da internet. $O$ conteúdo presente na rede e a quantidade de informação disponível sobre o comportamento dos usuários estão fazendo da internet uma fonte de pesquisa primordial inclusive para a indústria. A consulta a websites especializados em tendências, economia, política, estilos de vida, entre outros assuntos, e a perfis de influenciadores digitais nas redes sociais, blogs voltados a diversos setores $\mathrm{e}$ públicos-alvo é capaz de fornecer uma fonte inestimável e inigualável de informações sobre hábitos de vida e de consumo de diversos grupos e indivíduos seus comportamentos, valores e gostos.

Em se tratando dos bureaux, genericamente, seu trabalho consiste em fornecer análises precisas à construção da imagem de um produto. Porém, existe um aspecto altamente subjetivo que atua nesse processo: a intuição de cada um que trabalha num "bureau de estilo". Um exercício poético que, no entanto, dissimula o simples objetivo de vender mais e melhor, padronizando, de certa forma, sentimentos e atitudes - criando um campo em que a liberdade de escolha entre aquilo que nos agrada ou não é minuciosamente pré-determinado. Mas como tais conceitos podem ser transformados em produtos e atuar em nosso comportamento? E como uma visão tão particular de nossa realidade pode transitar nas decisões de importantes indústrias? (LEÃO, 2002).

Para que as marcas de moda levem em consideração as tendências do gosto coletivo divulgadas pelos bureaux no desenvolvimento de seus produtos, essas informações não podem, evidentemente, derivar do nada. Há um instrumento responsável pela previsão que recebe o nome de "pesquisa". Há também determinados indivíduos que são responsáveis por essa obtenção de informações. 
Em sua grande maioria são indivíduos ligados à arte e que assumem o papel de "agentes captadores" das transformações sociais. Não importa exatamente como são feitas essas pesquisas, mas simplesmente o fato de que elas servem como chancela para a previsão, que então passa a ser vista como resultado da observação e da mensuração (BERGAMO, 2007).

Muito afastados dos discursos de certos gurus da moda, os cadernos de tendências oferecem aos profissionais do setor indicações precisas que permitem a criação de uma coleção. Elas conseguiriam antecipar as tendências de maneira pertinente? Em certos casos sim, devido ao caráter autorrealizável dessas previsões. Fornecendo uma fonte de inspiração comum a vários criadores, os poucos nomes que contam na área contribuem para moldar as tendências. Os esboços de modelos propostos são usados como snacks criativos pelas agencias de estilo (ERNER, 2015).

Os olhos daqueles que trabalham nos "bureaux de estilo" são poderosos por captar instantes um gesto inusitado, uma atitude transgressora, um comportamento social que esteja sendo comum, igual entre alguns grupos de pessoas: um acessório em evidência, uma cor, um elemento que se sobressai de todo seu cenário. Algo novo, não medido, nem mencionado, sem violações ou intervenções. Usam da percepção e da sensibilidade para perceber algo que seja um signo de um tema prioritário (LEÃO, 2002).

É preciso sentir antes do grande público, verificar os encontros culturais, econômicos ou políticos que estão por vir (PENICAUT, 1994, p.99 apud LEÃO, 2002). Saber que aquilo que veem à sua frente poderá ser convertido em cores, tecidos e formas. Captar influências que, mais tarde, se transformarão em tendências de moda (LEÃO, 2002).

Viajando por todo o mundo, os coordenadores dos escritórios de estilo analisam tudo aquilo que pode ser convertido em moda, acompanhando todas as oscilações e evoluções que ocorrem no mercado de moda, suas carências ou saturações (muitas vezes de uma tendência estética ou comportamental), avaliando sempre as possíveis formas futuras de satisfazer os 
consumidores (LEÃO, 2002). São pesquisadores, criadores, ilustradores, maquetistas, etc, que tem como principal missão descobrir as tendências que afetarão o comportamento do consumidor e traduzi-las em guias para a criação.

Prever as tendências não depende de nenhum método analítico. Cada agência possui suas próprias receitas de fabricação, mas, para além das singularidades, uma mesma maneira de agir é recorrente. Em primeiro lugar, um quadro composto por palavras-chave que supostamente definem a época é elaborado. Esse compreende termos muito amplos. Para vestir essas palavras, os produtores dos cadernos se dedicam a um exercício de vigília. Eles se inspiram nos criadores de moda, mas também em outras áreas conexas, à frente das quais se encontra a arte contemporânea. Uma atenção particular é dada aos meios de vanguarda capazes de revelar a tendência do futuro. Por fim, inúmeras "corridas às vitrines" são organizadas, permitindo a troca de ideias pelo mundo, não apenas nas áreas têxteis (ERNER, 2015).

Toda esta precisa análise, já elaborada com dois anos de antecedência e baseada na descoberta de tendências econômicas, politicas, estéticas, culturais e, também, nas correntes de gostos, irão colaborar para a construção dos cadernos de tendências - uma sólida base de referências, comercializados, em media, com 18 a 20 meses de antecedência da estação a preços de 4000 a 60.000,00 dólares segundo o Bureau Arena \& Guelfin (1997 apud LEÃO, 2002).

Tradicionalmente, as agencias de estilo forneciam guias de antecipação criativa a seus clientes. Estes, quase sempre no âmbito da moda têxtil ou dos cosméticos, encontravam conselhos práticos sobre o que aconteceria dois anos depois. No entanto, essa periodicidade começou a evoluir, com a necessidade de propostas de "atualizações". Assim, ao lado de um período longo, são propostos intervalos de tempo mais curtos, de três a seis meses, com conselhos oportunistas sobre a estação em curso (ERNER, 2015).

As duas abordagens diferem, é claro. Antecipar uma tendência por dois anos supõe um verdadeiro 
trabalho criativo, bem como a definição, dentro dessas agências-conselhos, de planos de coleções articuladas em torno de temas, destinadas a uma ampla gama de clientes potenciais, desde grandes distribuidores até pequenas marcas que desejam reforçar sua equipe de criadores. Por outro lado, as antecipações de três a seis meses, com frequência, se limitam a fotografias tiradas em lugares da moda, passando uma ideia do ar do tempo, ou a uma leitura atenta da imprensa de moda e de suas paginas de celebridades (ERNER, 2015).

É importante ressaltar, porém, que os serviços dos bureaux atualmente não se limitam somente à área têxtil (do fio à confecção), desenvolvendo também ações para a indústria automobilística, de cosméticos, etc, além de prestar assessoria para as grandes marcas de moda do mundo todo (LEÃO, 2002).

É claro que existem também outras fontes de informações, das quais a grande maioria das empresas se serve, justamente por terem um caráter mais público e, sobretudo, por tais fontes serem muito mais acessíveis financeiramente. Nesse caso, existem duas importantes feiras de moda que acontecem na Europa, a Premiere Vision e a Interstoff. Além disso, há ainda a divulgação de tendências de moda no nível midiático, atuando sem intermediários sobre o alvo de todo este processo, que é o consumidor final (LEÃO, 2002).

No processo de criação estética dos bureaux, entretanto, existem duas etapas distintas: a primeira trata da busca de elementos estéticos que possam colidir e atender ao espirito do tempo (e isto inclui as tendências socioculturais, políticas, religiosas e econômicas) e seus respectivos "lifestyles". Esses elementos estéticos (formas, cores e materiais) serão avaliados, então, conforme estudos mercadológicos e a sua própria performance se já utilizados em estações anteriores. Os avanços tecnológicos são também um fator de extrema importância para a adequação da matéria-prima ao produto (LEÃO, 2002).

A segunda etapa é servir-se de todos os dados obtidos e concluídos, e reformulá-los conforme a ótica de cada escritório, o que, mais tarde, passará a figurar em palestras, cadernos de tendências, audiovisuais, 
etc, misturando todos os elementos das tendências de moda - cores, formas, materiais e temas conforme o repertório criativo daquele que o concebe, de sua sensibilidade e imaginação - que representa nuances sutis da nossa realidade e imaginação através de imagens, diluindo os elementos estéticos nos temas propostos às tendências de moda (LEÃO, 2002): Receita de uma Tendência de Moda: influências + cores + materiais + formas $=$ tema $=$ tendência .

Esses ingredientes formarão a receita que cada "bureau" preparará para as suas tendências de moda fator este que expressará a personalidade de cada escritório. Os elementos estéticos pesquisados integrarão os temas criados para as tendências. As cores, por exemplo, serão organizadas em famílias cromáticas e integrarão uma cartela de cores (LEÃO, 2002). Os materiais (tecidos e acabamentos) e as formas estéticas serão evocadas também a partir da análise rigorosa de influências e de outros aspectos, conforme seu desempenho na estação precedente. Ao mesmo tempo em que a tipologia da armação/ligamento está sendo pesquisada em função da disponibilidade de matérias-primas, das oscilações do gosto do consumidor, da cultura e épocas históricas. Linhas e formas são avaliadas conforme as características físicas/técnicas dos tecidos (SIMÕES, 1994, p.14 apud LEÃO, 2002).

A partir daí nascem os temas (os quais, geralmente, são divididos em quatro correntes) que integrarão, além de toda análise social já mencionada, uma ambiência - o ambiente que situa o tema, bem como as influencias e origens - e um lifestyle, ou seja, um segmento de mercado que indicará para quem o produto deverá ser dirigido. Por exemplo: romantismo ambiência nos anos 20, lifestyle de homens e mulheres de estilo clássico, couture como segmento de moda. Ou, se se dirige ao mercado adolescente, casualwear como segmento. Tudo dependerá da realidade mercadológica e social do momento para promover um determinado nicho de mercado e direcioná-lo a um ou outro segmento de moda (LEÃO, 2002). 
Muitos bureaux, ao formar seus temas, estruturam suas prescrições em análises sociológicas, psicológicas e semiológicas, tornando-as uma importante ferramenta para as empresas elaborarem toda a sua criação estética - fator que contribui para que a moda adquira o seu caráter ordinário (LEÃO, 2002).

Um outro aspecto emerge para uma padronização estética ainda maior: o fato de as prescrições viajarem o mundo através de seus vários representantes comerciais [e atualmente, do acesso aos portais dos bureaux de estilo disponível a assinantes do mundo todo]. Dessa forma, reafirma-se uma ótica muito particular de nossa realidade social, a qual está sendo moldada num ambiente estético altamente tendencioso, pois as antecipações, ao serem inseridas no contexto econômico, passam a integrar uma organização industrial sistemática, a qual descaracterizará todo o caráter idôneo das tendências de moda, que é a originalidade de suas influências (LEÃO, 2002).

Isso porquê os clientes dos bureaux são, geralmente, empresas que atuam na produção de matéria-prima para o setor de vestuário (e afins). Geralmente, empresas de corantes e têxteis, e, portanto, que se enquadram no primeiro nível na escala de produção industrial. No segundo nível estão as tecelagens, e no terceiro, as confecções (LEÃO, 2002). Todos estes setores passam a dar forma para seus produtos conforme a matéria-prima fornecida pelo seu antecessor na cadeia de produção, que, em sua grande maioria, se baseiam nas prospecções sugeridas pelos escritórios de estilo.

Hoje, porém, foi necessário aos bureaux oferecer uma nova proposta de trabalho - o de parceria - no sentido de garantir e fidelizar seus clientes, flexibilizando o seu relacionamento - de modo que cada marca agora pode solicitar e empregar as informações adquiridas de acordo com as suas escolhas $e$ necessidades mercadológicas, chegando até a montar seus próprios temas para as tendências de moda, baseados nas informações prestadas pelos bureaux. 
Porém, o mesmo caráter conformista ainda reside, como a persistência em se determinar variantes estéticas. O sistema já está viciado em oferecer (enquanto indústria) e aceitar (enquanto consumidor) (LEÃO, 2002).

Nesse sentido, observa-se que a imitação de determinados padrões estéticos e também comportamentais se torna legítima na nossa sociedade, na medida em que se submete às imposições mercadológicas de nosso mundo capitalista: não somos mais frutos dos acontecimentos, mas a resposta para códigos prescritos, ensinados (LEÃO, 2002). Fica a questão: conseguiriam os bureaux adivinhar as tendências de amanhã? A miríade de propostas que são formuladas e 0 grande número de soluções incorporadas tornam praticamente impossível responder a essa pergunta. No entanto, em sua obrigação de oferecer a cada estação novas tendências, eles sem duvida encorajam a inovação. Não podemos dizer o mesmo de alguns serviços lançados há pouco tempo na internet, como a WGSN (ERNER, 2015).

Seria possível vigiar constantemente o planeta moda? Aquilo que nenhum consultor de estilo podia fazer é hoje reivindicado pela WGSN. Sob essa sigla, encontramos uma sociedade chamada Worth Global Style Network, fundada em 1998, que se tornou o site número um em matéria de tendência, deixando os concorrentes - Stylesight, por exemplo - bem para trás. À maneira dos feed de notícias financeiros, esse site de serviços oferece a seus assinantes um panorama constante das tendências do momento (ERNER, 2015).

Esse quadro contínuo das tendências passa, num primeiro momento, por um acompanhamento disponibilizado por sucursais presentes em todos os continentes. A WGSN oferece relatórios sobre os principais acontecimentos da moda - salões ou desfiles, por exemplo - entregues a prazos muito curtos. Reportagens sobre butiques e lojas complementam as tradicionais corridas às vitrines, impossíveis de realizar em permanência. Por fim, o serviço propõe análises de tendências emergentes, especialmente alimentadas por 
um estudo contínuo dos meios de ponta, ou ainda dos novos criadores. A ambição desse serviço, com assinantes nas principais sociedades de moda, é oferecer ao mundo inteiro uma análise das tendências a curto prazo, entre três e seis meses, sobre as quais se baseia a renovação (ERNER, 2015). A consulta desperta a vertigem de uma informação imediata e exaustiva. Efeitos perversos podem ser esperados caso esse sistema, como podemos imaginar, se difunda no futuro. O papel de estimulo à inovação desempenhado pelos cadernos de tendências parecerá ultrapassado diante desse serviço em constante vigília das novidades na área da moda (ERNER, 2015).

Enquanto o discurso dos bureaux assume características próximas da profecia, que necessariamente tem um caráter de ruptura - atendendo às expectativas do discurso empresarial, os produtos, no caso cores, tecidos e formas, precisam ser deixados para trás para que novos possam sobrevir -, essa mesma ruptura pode ser observada quanto ao "saber" a respeito dos consumidores (BERGAMO, 2007). O que se sabe a respeito deles precisa ser constantemente deixado para trás para que novos "saberes" sobrevenham. A função dos bureaux é dizer quais são as mudanças ocorridas ou que estão para ocorrer e divulgá-las às marcas do setor. O discurso da tendência de moda alicerça-se, portanto, por um lado, na sua consonância com o discurso empresarial, ou seja, na crença de que se está falando do "consumidor de amanhã", e, por outro lado, numa informação propositalmente vaga (BERGAMO, 2007).

As empresas, em função disso, trabalham para produzir aquilo que a pesquisa anunciou como conhecimento. Dentro de dois anos encontraremos no mercado tudo aquilo que os bureaux disseram que as pessoas comprariam. Mesmo que as pessoas queiram comprar algo diferente, é o resultado da previsão que estará disponível no mercado. A consequência não é que o bureaux acertou a previsão, mas que os empresários, em função da crença de que estavam diante de um instrumento de conhecimento sobre o consumidor, fizeram o esforço, como resultado obvio, 
de conferir realidade à previsão. E a informação de tendência cobre toda a cadeia têxtil, desde a produção de fios e tintura até a roupa que será comprada em uma loja ou encontrada em alguma revista de moda (BERGAMO, 2007).

Não se trata, entretanto, nem de uma imposição pura e simples, nem de alguma forma de manipulação ou, mesmo por parte dos consultores de tendências, de algum engodo. Há uma hierarquia, um fluxo, de informações (BERGAMO, 2007): "sabendo que nosso próprio julgamento não tem valor, nos esforçamos para nos colocar sob o julgamento do resto do mundo [...]. Tentamos, assim, nos conformar ao comportamento da maioria ou da média. Nesse pequeno jogo, quem sai vencedor é aquele que adivinha o que a multidão vai fazer" (KEYNES, 1936 apud ERNER, 2015).

No domínio da moda, especular é imitar. É por isso que uma tendência vencedora pode eclipsar todas as outras. Uma forma, uma cor ou um sabor terá mais chances de triunfar sobre os rivais se todos pensarem, em dado momento, que ele será o vencedor em relação aos concorrentes (ERNER, 2015). O consumidor final, inclusive, também vem reforçar essa lógica, informando-se ele próprio sobre as tendências em voga em determinado momento e procurando consumir os objetos e peças de vestuário divulgados pelas revistas femininas, os blogs e sites especializados e os influenciadores.

Podemos dizer, portanto, que uma transformação está em curso no universo das tendências de moda. A instantaneidade com que as notícias do mundo da moda são veiculadas, as feiras e desfiles são cobertos e transmitidos pela imprensa e nas redes sociais, os materiais produzidos pelos escritórios de estilo são copiados e compartilhados; enfim: além da infinidade de conteúdo, a rapidez com que ele se alastra na rede, faz surgir um consumidor alinhado no eixo temporal com a própria indústria, encurtando sobremaneira os prazos entre pesquisa, previsão e produção. Consequência disto já é o movimento "see now, buy now", em que grandes marcas, como a inglesa 
Burberry, estão colocando à venda, nas suas lojas do mundo todo, as peças de determinada coleção imediatamente após o seu lançamento no desfile.

\section{CONCLUSÃO}

Independentemente de serem os bureaux de estilo a ditarem o que será tendência em um futuro próximo, ou de serem grupos sociais que mudam padrões de comportamento e consumo e os escritórios apenas observarem e captarem essas mudanças, de fato constata-se que a sociedade moderna processa ciclos de renovação periodicamente. O que é possível comprovar espontaneamente através das alterações no vestuário ao longo do tempo.

Não apenas as marcas de roupas, mas as marcas de diversos bens de consumo, e toda a indústria de forma generalizada, valem-se do conhecimento sobre tendências, deliberadamente ou até mesmo de forma intuitiva, para desenvolver alterações e inovações em seus produtos. Existe, de forma abrangente na sociedade moderna, a noção de que os indivíduos apreciam as mudanças, a novidade, e as empresas há mais de séculos demonstram esforços no sentido de agradar a esse anseio dos consumidores.

O conhecimento que falta à maior parte da população, genericamente, é o de que há um conceito que não só explica esse fenômeno, como é ele próprio o motor da sociedade moderna que movimenta as relações de consumo - a moda. Muitos foram os campos que se debruçaram nas últimas décadas a estudar esse ethos social, e o branding, como filosofia de trabalho dedicada à criação e manutenção de marcas, tem se valido do conhecimento sobre os ciclos da moda e sua influência no comportamento dos consumidores para gerenciar marcas de vestuário e outros produtos que precisam ser renovados $\mathrm{e}$ modificados ao longo do tempo para atender ao desejo pelo novo dos indivíduos.

Valendo-se ou não dos cadernos de tendências comercializados pelos bureaux de estilo ou de outras 
fontes de informações sobre tendências, seja no que tange a aspectos estéticos, de comportamento social ou de consumo, o fato é que as marcas de moda precisam estar atentas ao anseio por novidade que é intrínseco à cultura de nossa sociedade moderna, bem como observar em que direção esse desejo caminha, que tipo de produtos, formas, materiais, relações, valores, etc., tendem a agradar determinado grupo de consumidores no futuro próximo, para conseguir competir no mercado.

Fazer a gestão de marcas de moda na sociedade moderna diz respeito não só a estudar e aplicar conhecimentos de branding, como pesquisar e adotar informações de tendências em seus produtos. É preciso, ao mesmo tempo, conservar e reforçar os valores e características da marca, e promover transformações e inovações nos produtos. Necessita respeitar os valores culturais intrínsecos à sociedade, e as tendências efêmeras do consumo moderno.

\section{Referências}

AGUIAR, Titta. Personal Stylist: Guia para Consultores de Imagem. São Paulo: Senac, 2006.

BAUDRILLARD, Jean. A Sociedade de Consumo. Lisboa: Edições 70, 2008.

\section{For a Critique of the Political Economy of}

the Sign. United States of America: Telos Press Ltd., 1981.

BERGAMO, Alexandre. A Experiência do Status: roupa e moda na trama social. São Paulo: UNESP, 2007.

ERNER, Guillaume. Sociologia das Tendências. São Paulo: Gustavo Gili, 2015.

GOBÉ, Marc. BrandJam: O Design Emocional na

Humanização das Marcas. Rio de Janeiro: Rocco, 2007.

GOBÉ, Marc. A emoção das Marcas: conectando marcas às pessoas. Rio de Janeiro: Campus, 2002.

GOMEZ, Luiz S. R.; OLHATS, Magali; FLORIANO, Juliana.

Fashion's Brand DNA: the process. International

Conference Global Fashion: Creative and Innovative Contexts. Porto, 2010.

JOLY, Martine. Introdução à Analise da Imagem.

Campinas: Papirus, 2007. 
KOTLER, Philip.Marketing Management: the millennium edition. New Delhi: Ed. Prentice Hall, 2003.

KOTLER, Philip.Administração de Marcas. São Paulo: Atlas, 1998.

LEÃO, Joelma. Os "Bureaux de Style" e sua Ótica Sobre a Produção de Moda. Apud: Wajnman, M. Almeida, J A. Moda, Comunicação e Cultura - Um olhar acadêmico. São Paulo: UNIP Arte e Ciência, 2002.

LIPOVETSKY, Gilles. A Felicidade Paradoxal: ensaio dobre a sociedade de hiperconsumo. Lisboa: Edições 70, 2007.

o Crepúsculo do Dever: a ética indolor dos novos tempos democráticos. Lisboa: Publicações Dom Quixote, 2004.

Império do Efêmero: a moda e seu destino nas sociedades modernas. São Paulo: Ed. Companhia das Letras, 1989.

LOPES, Maria Vassalo Immacolata. Pesquisa em Comunicação. São Paulo - SP; Editora Loyola, 1990.

MAFFESOLI, Michel. A Parte do Diabo: resumo da subversão pós-moderna. Rio de Janeiro: Editora Record, 2004.

MARTINS, José Roberto. Branding: um manual para você criar, avaliar e gerenciar marcas. São Paulo: 2006. Disponível no site http://www.globalbrands.com.br

MESQUITA, Cristiane. A Moda Contemporânea: quatro ou cinco conexões possíveis. São Paulo: Ed. Anhembi Morumbi, 2004.

NEVES, José Luis. Pesquisa Qualitativa: características, usos e possibilidades. São Paulo - SP; FEA-USP, 1996.

SANT'ANNA, Mara Rubia. Teoria de Moda: sociedade, imagem e consumo. Barueri, Estação das Letras, 2007.

SANT' ANNA, Mara Rúbia. Sociedade e História. Apud: erevista ModaPalavra. Florianópolis, 2003.

SANT'ANNA, 1995. Citado em MESQUITA, Cristiane. A Moda Contemporânea: quatro ou cinco conexões possíveis. São Paulo: Ed. Anhembi Morumbi, 2004. Página 15.

SOLOMON, Michael R. O Comportamento do Consumidor: comprando, possuindo e sendo. Porto Alegre: Bookman, 2011.

STRUNK, Gilberto. Como Criar Identidades Visuais Para Marcas de Sucesso: um guia sobre o marketing das marcas e como representar graficamente seus valores. Rio de Janeiro: Rio Books, 2001.

TYBOUT, Alice M. \& CALKINS, Tim. Branding. São Paulo: Editora Atlas, 2006.

VOLLI, Ugo. Fascínio: Fetichismo e Outras Idolatrias. Lisboa: Fim de Século Edições, 2006. 